\title{
Transición de la prensa en el Ecuador desde 1906 hasta 2016, caso práctico diario El Comercio
}

\begin{abstract}
(ब)(1)

(c) $\underset{\mathrm{BY}(\mathrm{NC})(\mathrm{SA}}{\mathrm{Na}}$
\end{abstract}

Newspaper transition in Ecuador from 1906 to 2016, daily case study El Comercio

Ana Lucía Rivera Abarca. ${ }^{1}$, Héctor Oswaldo Aguilar Cajas. ${ }^{2}$, Heidy Elizabeth Vergara Zurita. ${ }^{3}$ \& Erika Nataly Alvarado Ramos. ${ }^{4}$

\begin{abstract}
.
DOI: https://doi.org/10.33262/concienciadigital.v4i3.1775

Introduction: El Comercio is an Ecuadorian newspaper that is 115 years old in the market. It is an independent newspaper that has evolved together with printing, technology, communication and the market. The Commercial Group in 2006 published a book in which it collects the first page of its publications for 100 years. Objective: The objective of this research is to determine the evolution of the newspaper El Comercio by applying the fundamentals of diagraming and composition to identify the handling and accommodation of text and image on the cover of its publications in these 110 years of history. Methodology: The qualitative methodology based on an observation sheet has been used, 14 publications are analysed, considering: the date of publication, the format ( descriptive graph applying a grid), the fundamentals: typography, colour and composition; the grid elements and a conclusion of the analysis carried out. Results: As a result, it is evident that each publication has its quality as the type of grid, the use of the typography, the color, the organization and distribution of the information that adapts to

\footnotetext{
1 Escuela Superior Politécnica de Chimborazo, Carrera de Mercadotecnia, Chimborazo, arivera@espoch.edu.ec, http://orcid.org/0000-0003-2594-2486

2 Escuela Superior Politécnica de Chimborazo, Carrera de Diseño Gráfico, Chimborazo, haguilar@espoch.edu.ec, http://orcid.org/0000-0002-2112-6492

3 Escuela Superior Politécnica de Chimborazo, Carrera de Diseño Gráfico, Chimborazo, heidy.vergara@espoch.edu.ec, http://orcid.org/0000-0002-6573-2339

${ }^{4}$ Universidad Estatal de Bolivar. Carrera de Turismo, Chimborazo, enalvarado@ueb.edu.ec, http://orcid.org/0000-0002-0163-633X
} 
the necessity of the time when it was published. Conclution: It can be concluded that since the first publication has worked on an organized and functional composition, the fundamentals of design are used in one of them, the use of typography, color and composition transcends to organize and hierarchize each compositional element used, it is evident $t$ he evolution until 2016 that reaches a functional publication for both a printed medium and a digital medium.

Keywords: evolution, layout, composition, typography, color, newspaper.

\section{Resumen.}

Introducción. El Comercio es un diario ecuatoriano que tiene 115 años en el mercado, es un periódico independiente que ha evoluciona junto con la imprenta, la tecnología, la comunicación y el mercado. El Grupo el Comercio en el año 2006 publicó un libro en el que recoge la primera página de sus publicaciones durante 100 años. Objetivo: Determinar la evolución del diario El Comercio mediante la aplicación de los fundamentos de la diagramación y la composición para identificar el manejo y acomodo de texto e imagen en la portada de sus publicaciones en estos 110 años de historia. Metodología: Se ha empleado la metodología cualitativa basado en una ficha de observación se analizan 14 publicaciones, considerando: la fecha de publicación, el formato (gráfico descriptivo aplicando una retícula), los fundamentos: tipografía, color y composición; los elementos de retícula y una conclusión del análisis realizado. Resultados: se evidencia que cada publicación tiene su cualidad como el tipo de retícula, el uso de la tipografía, el color, la organización y distribución de la información que se adapta a la necesidad de la época en la que fue publicada. Conclusión: Se puede concluir que desde la primera publicación se ha trabajado en una composición organizada y funcional, se utiliza los fundamentos del diseño en una de ellas, el uso de tipografía, color y composición trasciende para organizar y jerarquizar cada elemento compositivo utilizado, es evidente la evolución hasta el 2016 que llega a una publicación funcional tanto para un medio impreso como para un medio digital.

Palabras claves: evolución, diagramación, composición, tipografía, color, diario.

\section{Introducción.}

Las primeras páginas de un diario son el testimonio mas idóneo del transcurrir de la historia, son percepciones inmediatas que obedecen a los sucesos de cada día, que son transmitidos a quien debe conocer lo que sucede en su ciudad, en el país y en el mundo, es decir el pueblo. Estos portales informativos son desarrollados por periodistas, fotógrafos, diseñadores y editores bajo la percepción de un director o directora, cuya experiencia permite otear el horizonte y contextualizar el producto que diariamente se entrega al lector.

Desde los inicios se ha buscado organizar los textos e imágenes en diferentes soportes, y con la evolución de los medios impresos, se da también una transición del uso y acomodo de dichos elementos hasta la actualidad. 
Esta actividad involucra varios conocimientos referentes al diseño: ya que los textos y las imágenes que son los elementos que componen este tipo de medios deben ocupar un espacio, una jerarquía, una forma, un color, etc. Trasladando de esta forma el periodismo a la composición de la página, integrando los conocimientos de tipografía y creación de imágenes con los diversos canales que ofrecen las publicaciones digitales y las técnicas de impresión modernas.

\section{Materiales y métodos:}

\section{Fundamentación Teórica}

\section{Evolución de los medios impresos}

La importancia de los medios impresos se da desde que la humanidad busco la forma de comunicarse de una manera mas efectiva, mediante la impresión o transcripción de información, se considera que en China se dan los inventos que marcan la evolución de la página impresa: en el año 105 se inventó el papel, en el año 770 comienza a imprimirse en relieve, en el año 868 el primer libro impreso "EL SUTRA DEL DIAMANTE" mediante bloques de madera, a principios del siglo XV en Europa los escritores profesionales se unen a los monjes para la creación de libros y en el año de 1450 el orfebre Johannes Gutenberg inventa los tipos móviles (tipos fundidos o metálicos) y cinco años más tarde los emplea para comenzar a imprimir la tirada de 180 ejemplares de la llamada Biblia de Guterberg o Biblia de 42 líneas. En el año 1457 Gazzete, considerado el primer periódico impreso, que se imprime en Núremberg, Alemania. Aparece también el primer ejemplo de impresión a color con el Mainz Psalter, de Johna Fust y Peter Schöffer.

La introducción de la imprenta en América del Sur fue el instrumento material y técnico que abrió la puerta al desarrollo del periodismo escrito y la fundación de los primeros periódicos. El historiador José Antonio Benítez sitúa en Perú el primer periódico de América del Sur, seguido de los primeros periódicos de Colombia y Ecuador, a finales del siglo XVIII. (Universidad Técnica Particular de Loja, 2012)

Después de estos años se ven grandes evoluciones de los sistemas de impresión, el uso de color, la tipografías, las ilustraciones, la taquigrafía, gran tiraje, impresión en planchas de 4 colores, los periódicos, los grabados, maquina de escribir, litografía offset, mejora la calidad de impresión con nuevas maquinas, linotipia, mejora la composición tipográfica, fotocopiado, revistas especializadas y locales, creación de ordenadores, interfaz gráfica de usuario, programas de autoedición, fotografías a color en mayorías de medios impresos como el New York Times, el uso de la pág. web en periódicos, e-book, uso de Tablet, multiplicación de revistas independientes debido al bajo costo de producción. Estas son algunas de las innovaciones que han hecho de los medios impresos y ahora digitales evolucionen, considerando los medios, el merado, la economía, etc.

\section{Diseño Editorial}

El diseño editorial es un campo correspondiente al diseño gráfico que está destinado a la maquetación y composición estética de distintos elementos gráficos, para obtener medios 
impresos y digitales funcionales, tienen como finalidad transmitir un mensaje claro y preciso al grupo objetivo al cual está dirigido.

Lo que pretende el diseño editorial es: "Diseñar obras y difundirlas, comunicar eficientemente unas ideas a través de unas tipografías, colores, formas y composiciones que muestren una relación inequívoca del contenido que contiene" (Zanón, 2004, p.24).

Un proyecto editorial se ve inmerso en un proceso de continuo cambio, por ello un "proyecto editorial puede ser entendido como todo aquel conjunto de actuaciones, interrelacionadas y coordinadas, que tiene lugar alrededor de la edición de un contenido que puede resultar de interés para un determinado número de personas" (Gálvez, 2016, p.13)

\section{Fundamentos de la Diagramación}

"La diagramación, también llamada maquetación, es el proceso y el resultado de ordenar o distribuir los contenidos que integran cada una de las páginas de un periódico: textos, imágenes y publicidad" (López R, 2012)

Dentro de los fundamentos de la diagramación se deben considerar los fundamentos del diseño considerando: la tipografía, el color y la composición. Con el conocimiento de estos fundamentos se puede diseñar y diagramar un medio impreso o digital.

Considerando de esta forma que la tipografía - "técnica de componer distintos tipos para crear mensajes" (Jiménez A, 2016), va a comunicar de una forma más o menos atractiva cualquier texto, independientemente de su nivel de lectura, pero ante esta premisa se debe establecer características de la clasificación tipográfica serif y sans serif, o tipografías mas elaboradas como las rotuladas y las decorativas, además para utilizar las tipografías en diferentes textos se debe considerar la medida, el grosos, el ancho y la inclinación que pueden diferenciar un texto primario, secundario, terciario y complementario, en la escritura de párrafos el kerning, el trekking, las alineaciones y las sangrías pueden lograr que los textos se oxigenen y den mayor legibilidad. Buscando de esta forma un orden visual y facilitar la lectura. "Se entiende por composición el proceso en que los caracteres tipográficos son dispuestos en la línea de texto con intención de asegurar un orden visual y facilitar la lectura" (Jiménez A, 2016).

El color es el elemento que se ha vuelto indispensable a la hora diseñar cualquier medio sea impreso o digital, la forma como el color se puede aplicar: color denotativo representación o realismo (icónico, saturado, fantasioso), connotativo - emotividad o carisma (simbólico, psicológico, estético) y esquemático - funcional y codificación (emblemático, señalético y convencional), de tal forma que el color aplicado ya sea en gráficos, textos, fondos, manchas de color, etc. tengan un significado para el lector o sea una conexión entre la información y el mensaje. 
La composición debe considerar la jerarquía, la tensión, equilibrio y el ritmo, como normas compositivas que puede ayudar a distribuir gráficos, manchas de color, fondos, filetes, gráficos, textos que son los elementos compositivos de pág.

La construcción de una maqueta básicamente se trata de organizar el trabajo, lograr que fluya la comunicación y facilitar el manejo de la publicación al usuario. De ahí la importancia de que se cree una retícula que cumpla con las especificaciones y requerimientos de la publicación. (Zappaterra y Caldwell, 2014)

\section{Retícula}

La retícula es un conjunto de líneas, verticales y horizontales, que se reparten en una página cuya función es ayudar a ordenar y organizar los elementos gráficos. Las retículas evitan la distribución aleatoria de los elementos y aseguran una coherencia global de la maquetación. Este orden nos asegura que la información sea transmitida con claridad, relevancia y legibilidad. (Estrada, 2011)

Los elementos de retícula parten desde el formato que será la superficie donde se realizará la retícula, considerando un formato libre o normalizado, referente a las medidas estas dependen del fin del proyecto, de la cantidad de información, del medio.

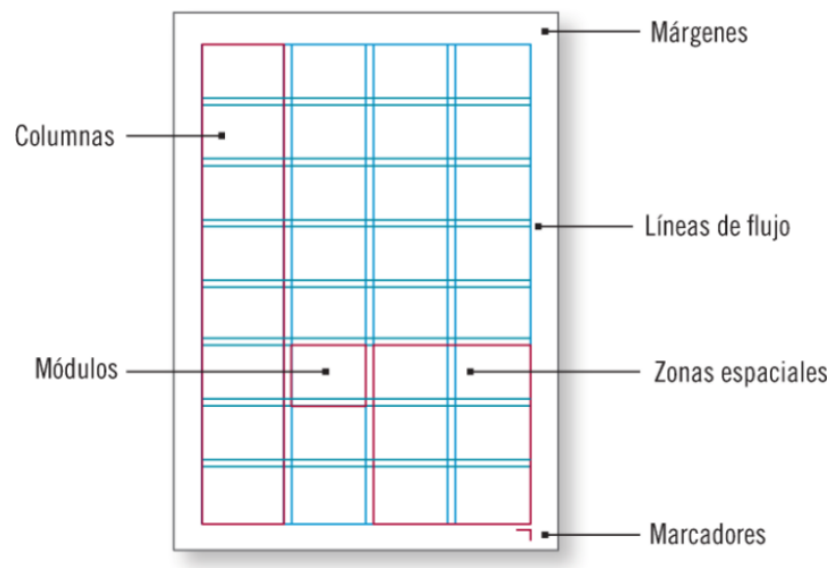

Fuente: Mariscal Romero, M. (2015).

Elaborado por: Los autores

\section{Elementos compositivos de página}

En el momento de diseñar y diagramar una página se debe considerar varios elementos que ayudan a que la información pueda ser interpretada, contada y organizada como: 


\section{ELEMENTOS COMPOSITIVOS DE PÁGINA}

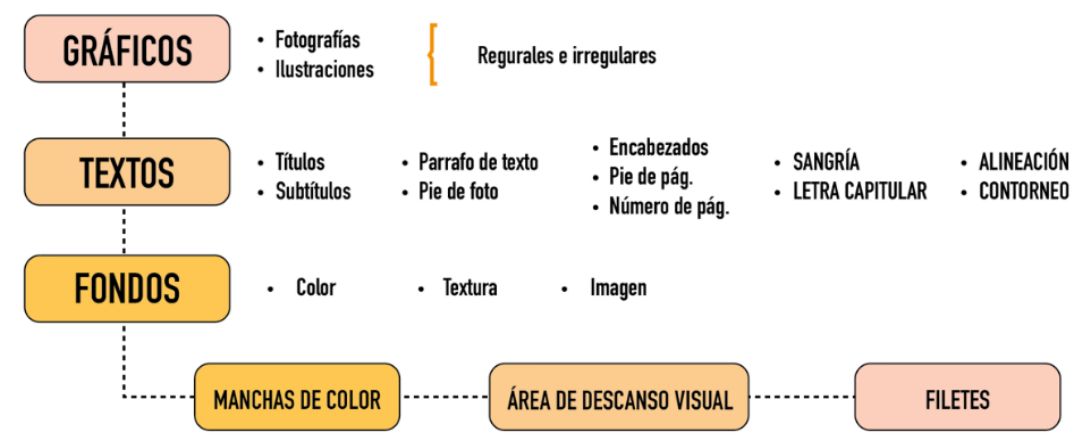

Fuente: Trabajo de Investigación

Elaborado por: Los autores

\section{Metodología.}

El método empleado es de carácter cualitativo, ya que esta investigación parte de la descripción de los fundamentos del diseño presentes en el diario El Comercio, dicho análisis se desarrolló por décadas desde el año 1906 hasta el año 1916, utilizando una matriz de análisis donde evidenciará el uso de los fundamentos de la diagramación y los elementos de retícula. Este análisis ayudará a evidenciar la evolución o transición que han tenido los medios impresos en el Ecuador, considerando hasta la última década con respecto a los medios digitales.

\section{Resultados.}

\section{Análisis del diario el comercio desde el año 1906 - 2016}

El diario el Comercio aparece en el año 1906 con su primera publicación impresa dando inicio a uno de los medios de comunicación en el Ecuador que ha evolucionado según las necesidades del medio, de tal manera que 90 años después el comercio hace su aparición en el internet de esa manera este diario sigue informando, ahora con el manejo de sus publicaciones en redes sociales. Se realiza un análisis gráfico de la primera pág. en un lapso de 110 años según su formato, fundamentos, elementos de retícula y conclusiones en cada período analizado. (Gonzales, M. 2016).

\section{Diario el comercio - $\mathbf{1 9 0 6}$}

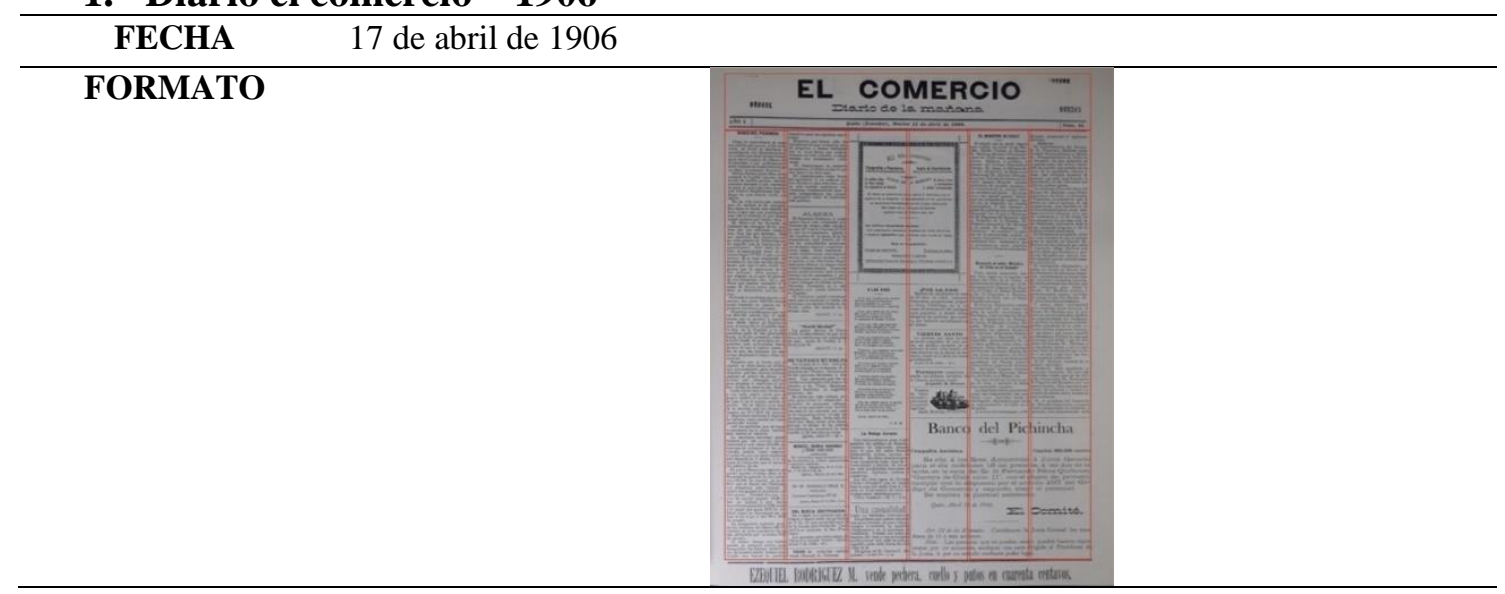




\begin{tabular}{|c|c|c|c|}
\hline & Tipografía & Color & Composición \\
\hline FUNDAMENTOS & $\begin{array}{l}\text { Encabezado: palo seco. } \\
\text { Subtítulos: palo seco. } \\
\text { Párrafos: romana. }\end{array}$ & $\begin{array}{l}\text { Texto negro y uso } \\
\text { de ilustraciones en } \\
\text { la publicidad. }\end{array}$ & $\begin{array}{l}\text { Jerarquía en el encabezado, } \\
\text { organización en las columnas } \\
\text { de texto, siendo una pág. } \\
\text { simétrica y equilibrada. }\end{array}$ \\
\hline $\begin{array}{l}\text { ELEMENTOS } \\
\text { DE RETÍCULA }\end{array}$ & \multicolumn{3}{|c|}{$\begin{array}{l}\text { Margen: mayor medida en el margen de corte, lomo; y pie por el texto adicional. } \\
\text { Caja: vertical } \\
\text { Columnas: } 6 \text { columnas regulares } \\
\text { Filas: } 3 \text { filas regulares } \\
\text { Medianil: regular corto } \\
\text { Módulos: } 18 \text { irregulares }\end{array}$} \\
\hline $\begin{array}{l}\text { Conclusión - } \\
\text { Sistema de } \\
\text { impresión }\end{array}$ & \multicolumn{3}{|c|}{$\begin{array}{l}\text { Al ser el primer ejemplar el sistema de impresión fue en una prensa manual, } \\
\text { donde se evidencia la rigidez de los tipos móviles y armado manual. }\end{array}$} \\
\hline
\end{tabular}

\section{Tabla 1. Diario El Comercio - 1906 Fuente: Elaboración propia.}

2. Diario el comercio - 1916

\begin{tabular}{|c|c|c|c|}
\hline FECHA & \multicolumn{3}{|l|}{1 de septiembre de 1916} \\
\hline \multirow[b]{3}{*}{ FUNDAMENTOS } & & $=$ EL COMERCIO & \\
\hline & \multirow{2}{*}{$\begin{array}{l}\quad \text { Tipografía } \\
\text { Encabezado: palo seco. } \\
\text { Subtítulos: palo seco. } \\
\text { Párrafos: romana. }\end{array}$} & Color & Composición \\
\hline & & $\begin{array}{l}\text { Texto negro y uso } \\
\text { de fotografías a un } \\
\text { solo color. }\end{array}$ & $\begin{array}{l}\text { Jerarquía en el encabezado y } \\
\text { en la foto central, } \\
\text { organización en las columnas } \\
\text { de texto, siendo una pág. } \\
\text { simétrica y equilibrada. Uso } \\
\text { de filetes de jerarquización. }\end{array}$ \\
\hline $\begin{array}{l}\text { ELEMENTOS DE } \\
\text { RETÍCULA }\end{array}$ & \multicolumn{3}{|c|}{$\begin{array}{l}\text { Margen: mayor medida en el margen de corte y lomo. } \\
\text { Caja: vertical } \\
\text { Columnas: } 7 \text { columnas regulares } \\
\text { Filas: no posee } \\
\text { Medianil: regular estrecho } \\
\text { Módulos: } 7 \text { establecidos por las columnas }\end{array}$} \\
\hline $\begin{array}{l}\text { Conclusión - } \\
\text { Sistema de } \\
\text { impresión }\end{array}$ & \multicolumn{3}{|c|}{$\begin{array}{l}\text { El sistema de impresión fue en una prensa manual, este sistema se mantiene por } \\
\text { varios años. Este tipo de diagramación se mantienen por } 20 \text { años hasta febrero } \\
1936\end{array}$} \\
\hline
\end{tabular}




\begin{tabular}{|c|c|c|}
\hline FЕСНА & 8 de marzo de 1936 & \\
\hline FORMATO & & $\begin{array}{l}\text { EL COMERCIO } \\
\text { Sensacional golpe de Hitterconmueve a Europa } \\
\text { (1) }\end{array}$ \\
\hline FUNDAMENTOS & \begin{tabular}{l}
\multicolumn{2}{c}{ Tipografía } \\
Encabezado: palo \\
seco. \\
Subtítulos: palo seco. \\
Párrafos: romana.
\end{tabular} & \begin{tabular}{lrl}
\multicolumn{2}{c}{ Color } & \multicolumn{2}{c}{ Composición } \\
Texto negro & y & Jerarquía en el encabezado y en la \\
uso & de & ilustración central, modificación \\
fotografías & e & en la organización de los \\
ilustraciones a un & elementos compositivos en la \\
solo color. & & retícula, creando un diseño mas \\
& & complejo y separado por filetes \\
& para crear orden de lectura.
\end{tabular} \\
\hline $\begin{array}{l}\text { ELEMENTOS DE } \\
\text { RETÍCULA }\end{array}$ & \multicolumn{2}{|c|}{$\begin{array}{l}\text { Margen: medidas iguales en los } 4 \text { márgenes. } \\
\text { Caja: vertical } \\
\text { Columnas: } 8 \text { columnas regulares } \\
\text { Filas: irregulares } \\
\text { Medianil: regular estrecho } \\
\text { Módulos: varios módulos irregulares que se basan en las } 8 \text { columnas de la retícula }\end{array}$} \\
\hline $\begin{array}{l}\text { Conclusión - } \\
\text { Sistema de } \\
\text { impresión }\end{array}$ & \multicolumn{2}{|c|}{$\begin{array}{l}\text { El sistema de impresión fue en una prensa manual, este sistema se mantiene por } \\
\text { varios años. }\end{array}$} \\
\hline
\end{tabular}

Tabla 3. Diario El Comercio - 1936

Fuente: Elaboración propia.

4. Diario el comercio - 1966

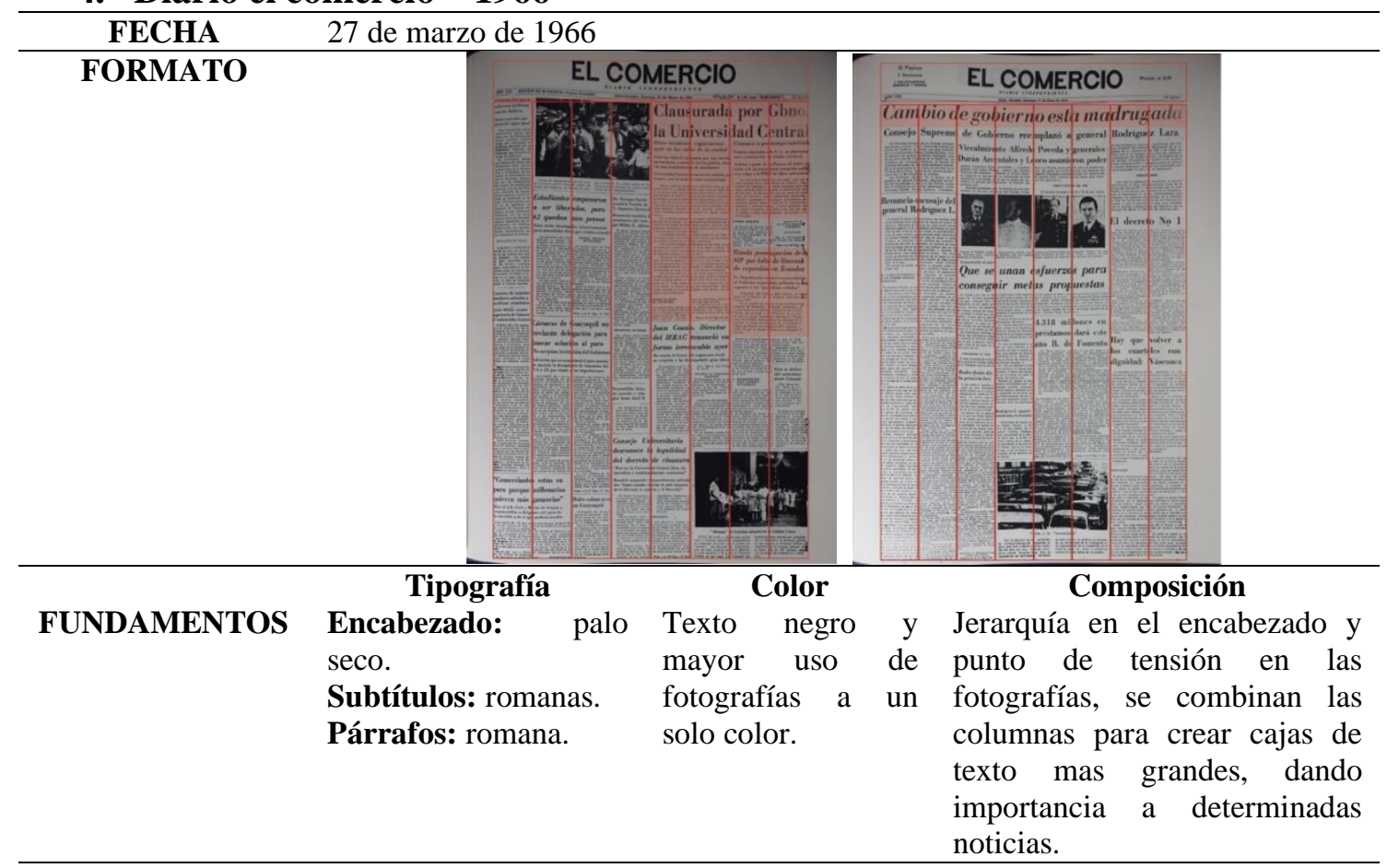




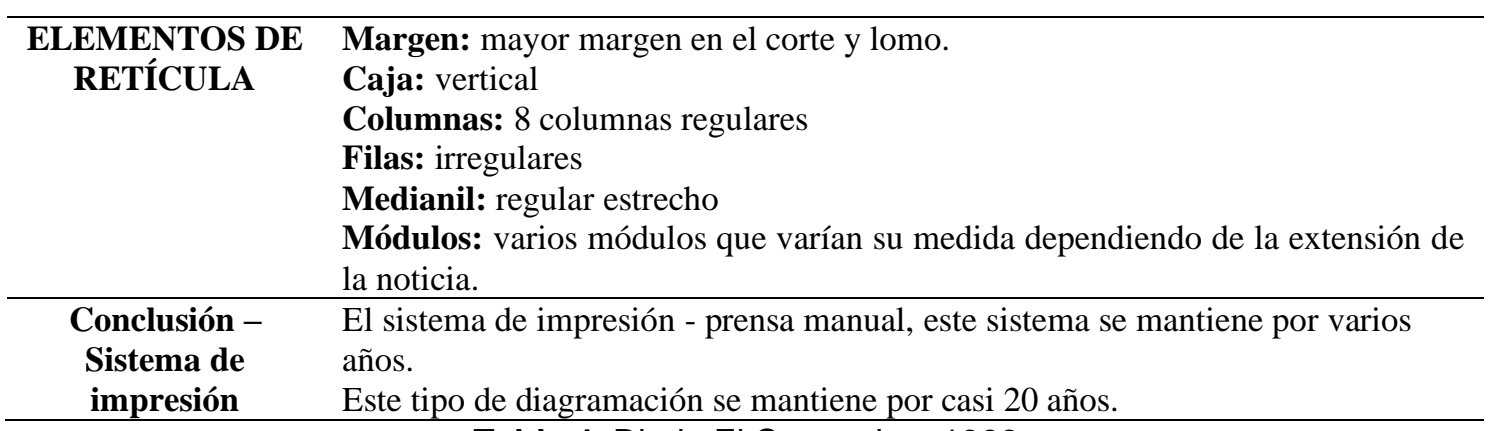

Tabla 4. Diario El Comercio - 1966

Fuente: Elaboración propia.

5. Diario el comercio - 1986

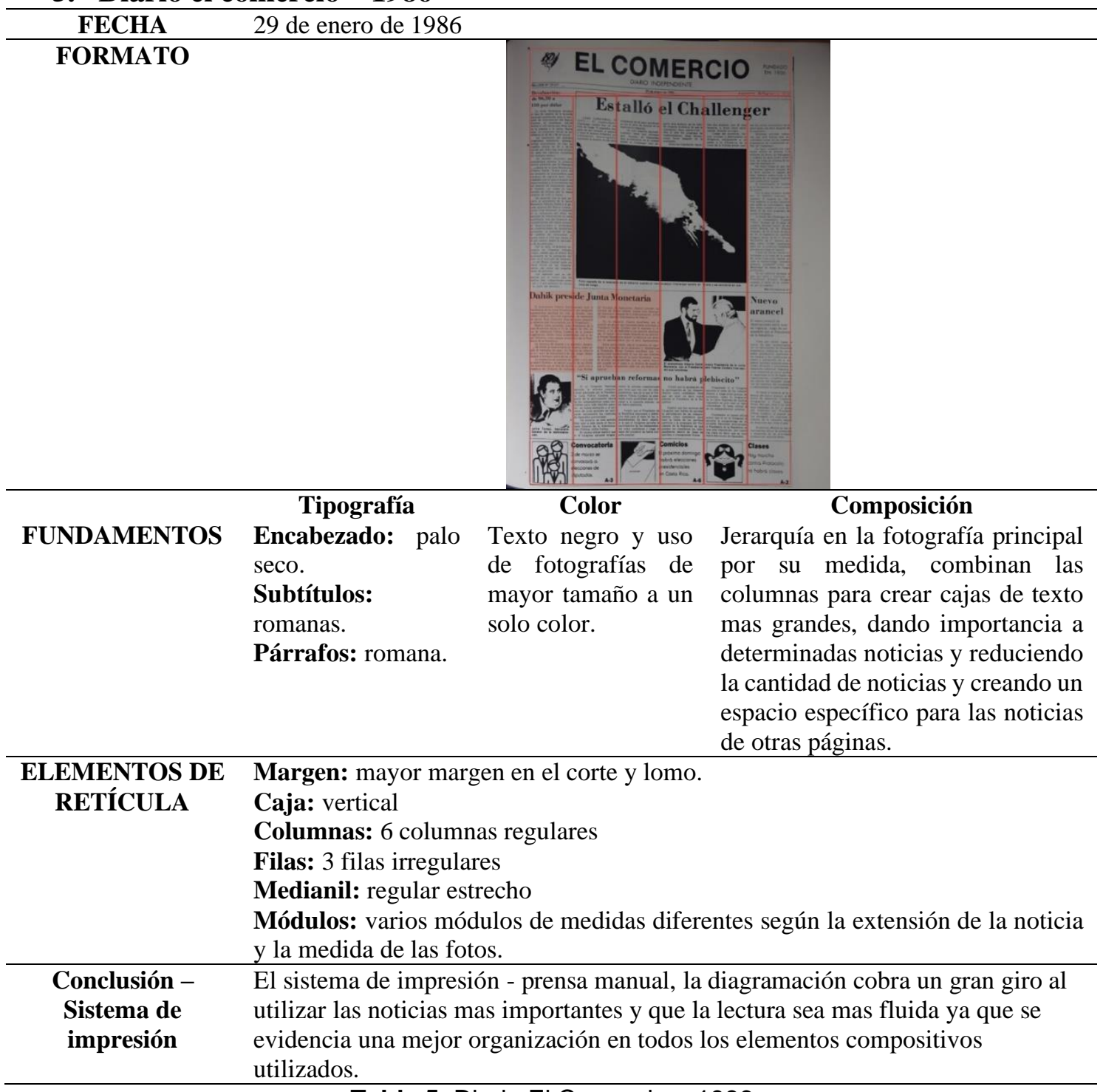

Tabla 5. Diario El Comercio - 1986

Fuente: Elaboración propia. 
6. Diario EL COMERCIO - 1986 - 1993

FECHA 2 de junio de $1986 / 14$ de septiembre de 1993

FORMATO

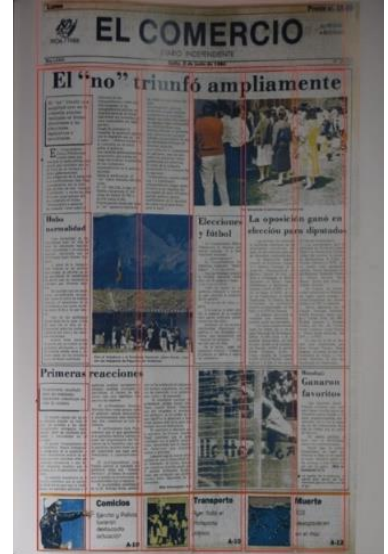

Color

\section{Tipografía}

FUNDAMENTOS Encabezado: palo seco.

Subtítulos:

romanas.

Párrafos: romana.

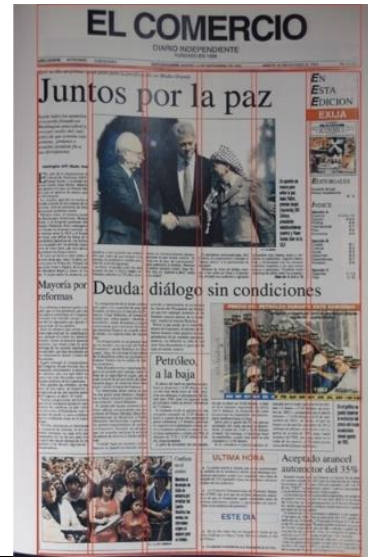

\section{Composición}

Jerarquía en el encabezado, al ser la primera edición de full color, las imágenes generan puntos de tensión en el lector, busca el equilibrio al utilizar las columnas o combinándolas para diagramar una solo noticia.

ELEMENTOS DE Margen: mayor margen en el corte y lomo.

RETÍCULA Caja: vertical

Columnas: 6 columnas regulares

Filas: 5 filas irregulares, 2 de ellas son destinadas para el encabezado y los temas de los otros artículos

Medianil: regular y más amplio

Módulos: varios módulos de medidas diferentes según la extensión de la noticia y la medida de las fotos.

Conclusión - $\quad$ Sistema de impresión offset, el uso del color atrae la atención a la información, Sistema de se evidencia mayor organización que ayuda a la fluidez en la lectura de la

impresión información. Utilizan filetes de separación delimitar cada noticia. Uso de letra capitular en el primer párrafo de texto.

Tabla 6. Diario El Comercio - 1986 - 1993

Fuente: Elaboración propia.

7. Diario el comercio - $1996-2003$

FECHA 6 de marzo de 1996 / 19 de octubre de 1998 / 5 de marzo de 1999/ 26 de marzo de 2003

FORMATO




\begin{tabular}{|c|c|c|c|}
\hline & & 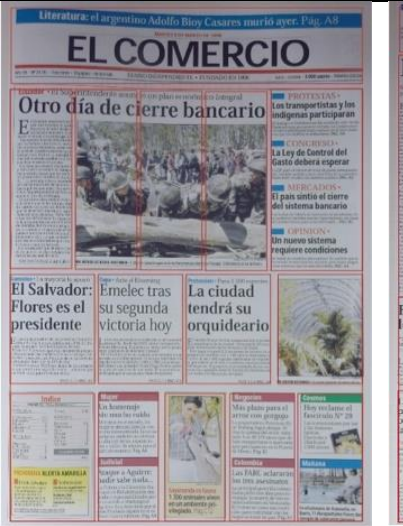 & 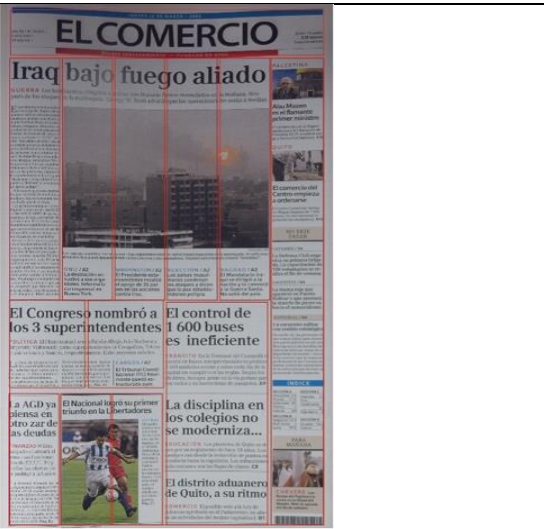 \\
\hline FUNDAMENTOS & $\begin{array}{l}\text { Tipografía } \\
\text { Encabezado: } \\
\text { palo seco. } \\
\text { Subtítulos: } \\
\text { romanas. } \\
\text { Párrafos: } \\
\text { romana. }\end{array}$ & $\begin{array}{l}\text { Color } \\
\text { Texto negro, aplican } \\
\text { color azul y rojo en } \\
\text { textos secundarios, el } \\
\text { uso del full color en las } \\
\text { fotografías y manchas de } \\
\text { color, en esta transición } \\
\text { se ve la aplicación del } \\
\text { degradado usado en una } \\
\text { mancha de color en el } \\
\text { último año. }\end{array}$ & $\begin{array}{l}\text { Composición } \\
\text { Jerarquía en el encabezado, las } \\
\text { imágenes generan puntos de } \\
\text { tensión en el lector, modificando } \\
\text { sus medidas para crear un } \\
\text { dinamismo intencionado, existe } \\
\text { fragmentación en las columnas para } \\
\text { colocar textos complementarios } \\
\text { como pie de foto, la parte inferior } \\
\text { se divide para colocar las noticias } \\
\text { mas importantes de todo el } \\
\text { periódico. }\end{array}$ \\
\hline
\end{tabular}

ELEMENTOS DE Margen: mayor margen en el corte y lomo.

RETÍCULA Caja: vertical

Columnas: se trabaja con 6 columnas irregulares y 5 columnas.

Filas: 4 filas irregulares en donde se distribuyen toda la información.

Medianil: variado porque se evidencia combinación de módulos.

Módulos: varios módulos de medidas diferentes, se busca dar una ubicación a los titulares mas representativos de las páginas internas, e incluso se crean módulos de mayor medida para jerarquizar cierta información.

Conclusión - $\quad$ Sistema de impresión offset, el uso del color atrae la atención a la información,

Sistema de en estos 4 años se ven ligeras modificaciones buscando mejorar la organización

impresión de los elementos y se busca dar una información corta para llamar a las pág. internas, se emplean filetes de separación, manchas de color (colores planos) y aparecen los gradientes para llamar la atención de la información. Se visualiza una diagramación mas espaciada creando nuevos espacios para distribuir la información de una mejor forma.

Tabla 7. Diario El Comercio - 1996 - 2003

Fuente: Elaboración propia.

8. Diario EL COMERCIO - 2006

FECHA 1 de enero de 2006

FORMATO 
Vol. 4, N³, p. 126-140, julio - septiembre, 2021

\begin{tabular}{|c|c|c|c|}
\hline \multirow[b]{2}{*}{ FUNDAMENTOS } & \multicolumn{2}{|l|}{ Tipografía } & \multirow[b]{2}{*}{$\begin{array}{l}\text { Composición } \\
\text { Jerarquía en el encabezado, al ser } \\
\text { una gran noticia dividen a la pág., } \\
\text { por la mitad para jerarquizar la } \\
\text { información, se da mas rectitud al } \\
\text { utilizar tipo sin serifa, el mayor } \\
\text { peso visual en } 2 \text { fotos por medida y } \\
\text { ubicación, dan jerarquía de } \\
\text { posición a dos noticias } \\
\text { colocándolas en la parte superior, } \\
\text { jugando con esa modificación en la } \\
\text { primera plana. }\end{array}$} \\
\hline & $\begin{array}{l}\text { Encabezado: palo } \\
\text { seco. } \\
\text { Subtítulos: palo } \\
\text { seco. } \\
\text { Párrafos: romana. }\end{array}$ & $\begin{array}{l}\text { Texto negro, } \\
\text { aplican color azul y } \\
\text { rojo en textos } \\
\text { complementarios, } \\
\text { manchas de color } \\
\text { para fondos } \\
\text { completos de } \\
\text { noticias o textos } \\
\text { específicos. } \\
\text { Identificador de los } \\
100 \text { años junto al } \\
\text { titular. }\end{array}$ & \\
\hline RETÍ & \multicolumn{3}{|c|}{$\begin{array}{l}\text { Margen: mayor margen en el corte y lomo. } \\
\text { Caja: vertical } \\
\text { Columnas: } 4 \text { columnas regulares en la parte superior y } 5 \text { columnas irregulares en } \\
\text { la parte inferior. } \\
\text { Filas: } 4 \text { filas irregulares en donde se distribuyen toda la información. } \\
\text { Medianil: irregulares en la parte inferior. } \\
\text { Módulos: } 8 \text { módulos irregulares de gran tamaño en } 3 \text { noticias y subdivido en la } \\
\text { parte superior para el titular y las } 2 \text { noticas extras. }\end{array}$} \\
\hline $\begin{array}{l}\text { Conclusión - } \\
\text { Sistema de } \\
\text { impresión }\end{array}$ & \multicolumn{3}{|c|}{$\begin{array}{l}\text { Sistema de impresión offset, se usa mas color como en la identificación de } 100 \\
\text { años, se genera mayor regularidad, por tener menos noticias para resaltar la } \\
\text { noticia mas importante, un diseño mas limpio al no tener tantos módulos que } \\
\text { segmenten las noticias, fluidez de lectura. Una un código de barra que idéntica } \\
\text { el número de publicación. }\end{array}$} \\
\hline
\end{tabular}

Tabla 8. Diario El Comercio - 2006

Fuente: Elaboración propia.

\section{Diario el comercio - 2016}

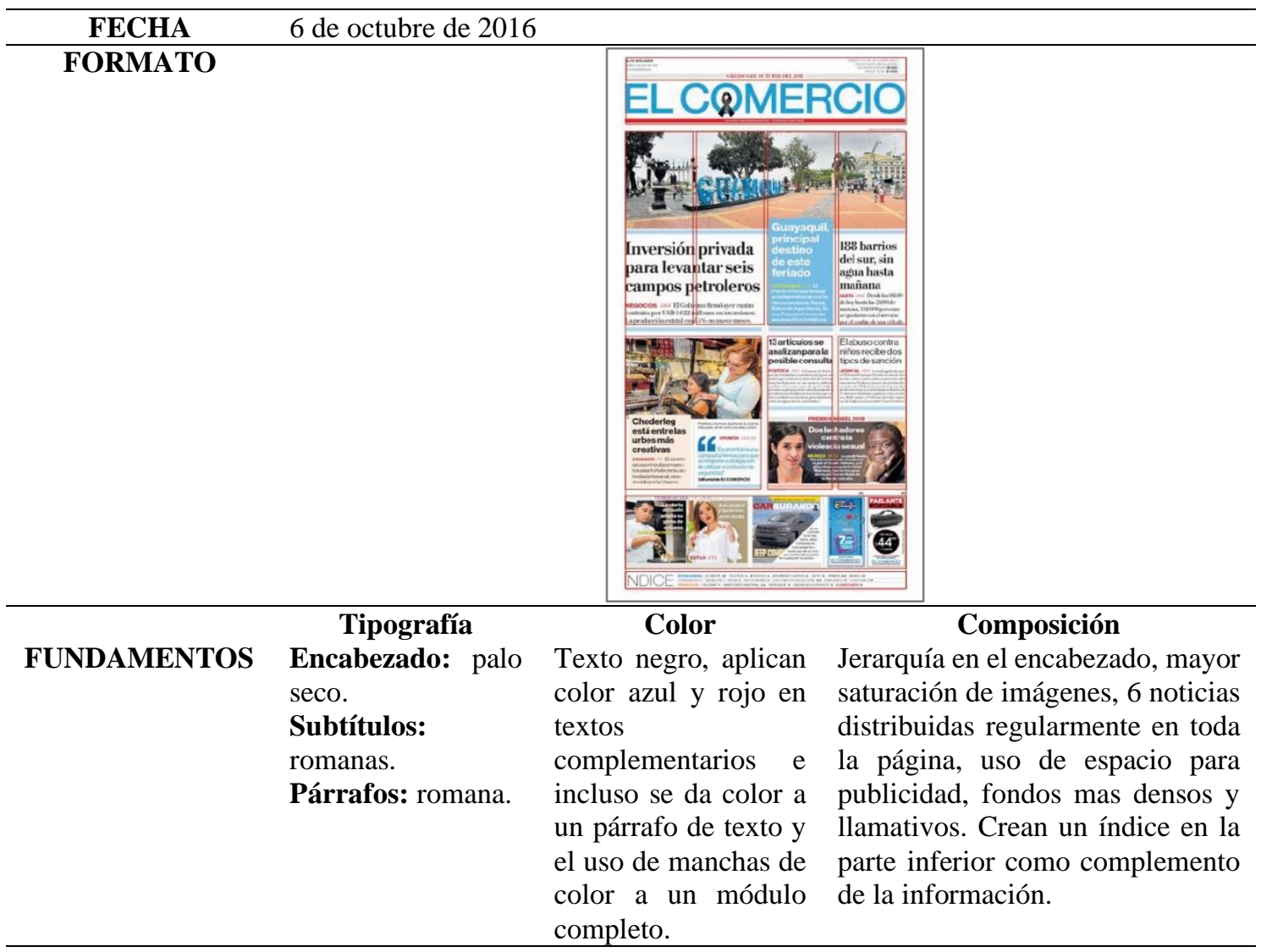




\begin{tabular}{cl}
\hline ELEMENTOS DE & Margen: mayor margen en el corte y lomo. \\
RETÍCULA & Caja: vertical \\
Columnas: 4 columnas regulares \\
& Filas: 5 filas irregulares en donde se distribuyen toda la información. \\
& Medianil: regular, más amplio. \\
& Módulos: varios módulos de medidas semejantes, creando mayor orden y \\
& regularidad en toda la pág. Uso de filetes de separación de gran tamaño que divide \\
& en filas pronunciadas. \\
\hline Conclusión - & Sistema de impresión offset, con un tiraje menor, ya que el comercio ahora \\
Sistema de & también es digital, el lector puede descargar el periódico completo en formato \\
impresión & digital o lo puede leer dese la web, por tal razón se busca la regularidad para no \\
& crear cansancio visual al lector al tener que leer en pantalla. El uso del color es \\
& mas notorio, pero con tonos suaves dando mas espacio a la fotografía principal \\
& de 4 módulos completos. Un cambio sutil pero moderno para que sea funcional \\
& para un medio impreso y digital. \\
\hline
\end{tabular}

Tabla 9. Diario El Comercio - 2016

Fuente: Elaboración propia.

\section{Discusión:}

Este estudio se desarrollo basado en a la recolección de noticias del libro: Centuria LAS NOTICIAS de los 100 años, publicado por el diario el Comercio en su aniversario número 100. Considerando el diseño de la primera pág. que fue publicada, analiza el proceso evolutivo considerando el formato, los fundamentos: tipografía, color y composición, el uso de los elementos de retícula según el número de columnas y la distribución de la información, el modo de impresión, además el uso y aplicación de los elementos compositivos que evidencia el desarrollo tecnológico y gráfico, considerando 100 años de publicaciones constantes en los cuales se hace error y prueba para llegar de mejor forma al lector.

\section{Conclusiones.}

- La importancia de la composición se da desde el primer ejemplar en el cual distribuyen la información mediante 6 columnas regulares, el encabezado es el elemento jerárquico, utilizan filetes para separar las noticias y disponen espacio para la publicidad, con el paso de los años se mantienen los elementos, pero la retícula se modifica con el uso de las filas para dar dinamismo a la pág. y creando una retícula irregular.

- El uso de la tipografía ha evolucionada por el modo de impresión de cada ejemplar, al inicio la tipografía serif con estilos como: grosor, inclinación, medida; utilizando los tipos móviles de la imprenta de inicios, posteriormente las tipografías son mas legibles, menos ornamentales, con variaciones de medidas mas notorias y posterior a ello con diferente color, la legibilidad por el tipo de impresión offset es evidente.

- El uso del color da un cambio evidente en los ejemplares que desde el 15 de abril de 1986 aparecen los primeros gráficos a color y en el mismo año fueron las fotografías a color que dan el cambio a la primera página del diario, con el pasar del tiempo se incorpora color a los filetes, textos y manchas de color, dando vida a cada publicación.

- La transición de la prensa en estos 110 años del Comercio ha pasado por grandes 
cambios cada uno de ellos acompañados por la evolución de la imprenta, la tecnología y la comunicación, hasta la actualidad que se ha dejado de imprimir grandes tirajes de periódicos para ser leídos en la web.

\section{Referencias bibliográficas.}

Alcázar Jiménez, N. (2016). Definición y diseño de productos editoriales (UF1904). IC Editorial.

Castro Tirado, M. Á. (2016). Maquetación de productos editoriales: UF1461. IC Editorial.

El Comercio. (2006). Centuria LAS NOTICIAS de los 100 años. Edición El Comercio.

Gálvez Clavijo, I. y Orellana Pelayo, M. G. (2016). Gestión del producto editorial (UF1900). IC Editorial.

Gonzales, M. (2016). Perfil de los periodistas digitales en Ecuador: estudio de seis diarios nacionales de información general en su versión digital. Serbiluz, vol. 32. http://www.redalyc.org/articulo.oa?id=31048480042

López Cubino, R. (2012). La diagramación del periódico: proyecto Mediascopio Prensa. La lectura de la prensa escrita en el aula. Ministerio de Educación y Formación Profesional de España.

Mariscal Romero, M. (2015). Órdenes de producción, equipos y páginas maestras para la maquetación y compaginación de productos gráficos (UF1373). IC Editorial.

Universidad Técnica Particular de Loja, (2012). Anuario de las Empresas de Comunicación de Ecuador. Editorial UTPL.

Zanón, D. (2004). Introducción al Diseño Editorial. Editorial Visión Libros.

Zappaterra, Y. y Caldwell, C. (2014). Diseño editorial: periódicos y revistas / medios impresos y digitales. Editorial Gustavo Gili.

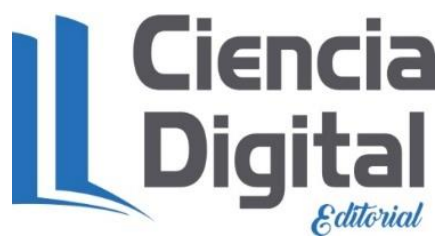


PARA CITAR EL ARTÍCULO INDEXADO.

Rivera Abarca, A. L., Aguilar Cajas, H. O., Vergara Zurita, H. E., \& Alvarado Ramos, E. N. (2021). Transición de la prensa en el Ecuador desde 1906 hasta 2016, caso práctico $\begin{array}{llll}\text { diario El Comercio. } & \text { ConcienciaDigital, } & \text { 4(3), } & \text { 126-140. }\end{array}$ https://doi.org/10.33262/concienciadigital.v4i3.1775

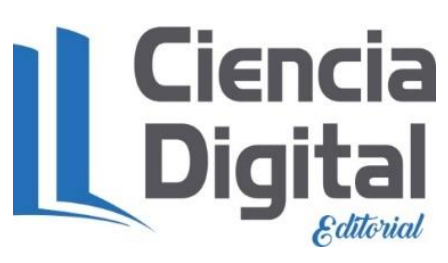

El artículo que se publica es de exclusiva responsabilidad de los autores y no necesariamente reflejan el pensamiento de la Revista Conciencia Digital.

El artículo queda en propiedad de la revista y, por tanto, su publicación parcial y/o total en otro medio tiene que ser autorizado por el director de la Revista Conciencia Digital.
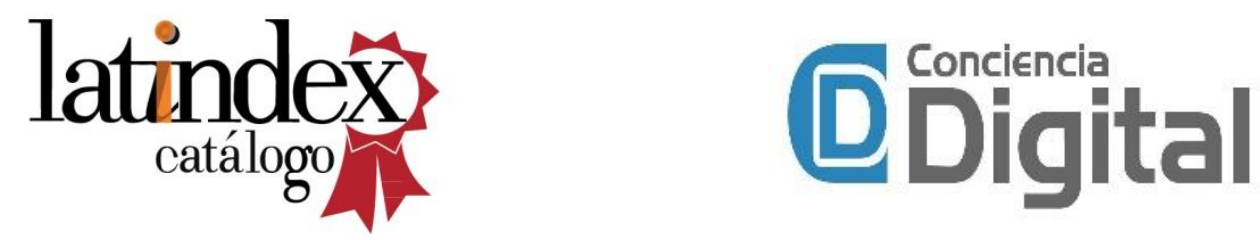